\title{
Floral Diversity and Genetic Structure of Tea Germplasm of Sri Lanka
}

\author{
Mahasen Achintiya Bandara Ranatunga, ${ }^{1}$ Jeevan Dananjaya Kottawa Arachchi, \\ Kumudini Gunasekare, ${ }^{2}$ and Deepthi Yakandawala ${ }^{3}$ \\ ${ }^{1}$ Plant Breeding Division, Tea Research Institute of Sri Lanka, 22100 Talawakelle, Sri Lanka \\ ${ }^{2}$ Ministry of Primary Industries, West Tower World Trade Center, Level 18, 00100 Colombo, Sri Lanka \\ ${ }^{3}$ Department of Botany, Faculty of Science, University of Peradeniya, 20400 Peradeniya, Sri Lanka \\ Correspondence should be addressed to Mahasen Achintiya Bandara Ranatunga; mahasenab@yahoo.com
}

Received 30 May 2017; Accepted 2 August 2017; Published 19 September 2017

Academic Editor: Alexandre Sebbenn

Copyright @ 2017 Mahasen Achintiya Bandara Ranatunga et al. This is an open access article distributed under the Creative Commons Attribution License, which permits unrestricted use, distribution, and reproduction in any medium, provided the original work is properly cited.

\begin{abstract}
The role of tea germplasm in crop improvement, though well recognized, yet lacks sufficient information depriving its optimum use. About 600 accessions are conserved as tea germplasm in Sri Lanka and only $4 \%$ have been frequently utilized in breeding. Floral morphological characters are useful descriptors for preliminary characterization of genetic resources and particularly pistil traits are considered as reliable criteria in taxonomical studies of higher plants. The objectives of the present study were to conduct a comprehensive analysis on floral diversity of tea germplasm to determine the nature and extent of genetic structure of tea germplasm and to categorize accessions into major taxa. Eighty-nine accessions from the tea germplasm were characterized using 16 floral traits. Results indicated presence of considerable variation among germplasm accessions. Accessions were categorized into five different groups based on the diversity of floral traits and highly discriminating accessions were identified based on the grouping pattern. Among the traits, pistil traits were highly variable compared to other traits. Tea germplasm is predominantly represented by Cambod type accessions (68\%) followed by Assam types (20\%). Availability of China type accessions is low. Gaps in the germplasm collection were identified and information generated can be used for decision making in future germplasm exploration missions and breeding programme.
\end{abstract}

\section{Introduction}

Tea germplasm is the most valuable fundamental materials for tea breeding and biotechnology with a huge potential for the whole tea industry in the future [1]. The role of germplasm in crop improvement, though well recognized, still lacks sufficient information on the performance of the germplasm collection and has led to its limited use. Currently, about 600 tea germplasm accessions are being maintained at the Tea Research Institute of Sri Lanka, Talawakelle, Sri Lanka [2]. However, these accessions are not adequately evaluated for biochemical, agronomic, and molecular traits [3,4]. Hence, tea crop improvement programmes are being practiced on a narrow genetic base. According to the records, only 23 accessions ( $4 \%$ of the total germplasm) have been frequently utilized in tea breeding programmes as parents in the past couple of decades to develop new cultivars [5]. The limited genetic diversity of tea renders it more vulnerable to stress conditions such as the effect of pests, diseases, and drought. Therefore, there is an urgent need to evaluate the existing germplasm to utilize them in tea breeding programmes.

Tea, Camellia sinensis (L) O. Kuntze., has been classified into below species level and they are C. sinensis var. assamica (Assam type) and C. sinensis var. sinensis (China type) [6]. The third type referred as Cambod or Southern form as a subspecies of $C$. assamica was recognized by Wight [7]. Tea is an allogamous plant and all tea taxa freely interbreed and thus show many overlapping morphological, biochemical, and physiological attributes that are highly diverse and heterozygous [8]. Because of the extreme hybridization, existence of 
the pure archetypes of tea is doubtful [8]. Therefore, it is important to characterize accessions in the tea germplasm for genetic structure that would assist in better management and utilization of the available genetic resources.

Plant morphology is considered as the scientific study of the physical form and external structure of plants and can be applied to carve up diversity into its systematic subunits [9]. Morphological characters are useful descriptors for preliminary characterization of genetic resources and varietal identification, as they are cost effective compared to biochemical and molecular markers [10]. Among the morphological descriptors, floral traits are important and can be used as taxonomic indicators which are considered informative in identifying the relationship among species of the same genus [11].

Despite the several disadvantages such as continuous variations and high plasticity, influenced by environmental factors, morphological characters are the most adopted markers used by tea breeders globally. Therefore, in tea, morphological descriptors have been used for characterization [12], genetic diversity and comparison [13, 14], cultivar identification [15], and phylogeny and classification studies [16-18]. A comprehensive phylogenetic analysis of all genera belonging to the plant family Theaceae was conducted [18]. It has been reported that the numerical taxonomy and cladistic analysis based on morphological characters of floral organ are useful in species classification of genus Camellia [11]. Also, the taxonomic position of the wild tea plant (C. sinensis (L.) O. Kuntze forma formosensis Kitamura) was assessed using morphological traits [16] and the potential of the intraspecific classification of tea plant based on the variations of floral morphology and numerical taxonomy was reported [12].

Several attempts have been made to characterize tea genetic resources in Sri Lanka using morphological descriptors $[2,19,20]$. Characterization of 203 tea germplasm accessions using 35 standardized vegetative descriptors to assess the phenotypic diversity has been reported and identified minimum list of descriptors suitable as morphological markers that are useful in characterization of tea germplasm in Sri Lanka [20]. Another study has been conducted to assess the variability of pistil related characters to be used as a measure of genetic diversity in tea germplasm using 27 accessions [21]. However, this study has employed only six floral traits to characterize a limited number of germplasm accessions. Therefore, it is important to use a large number of floral traits and germplasm accessions in order to comprehensively analyze the diversity of tea germplasm in Sri Lanka.

Hence, the objective of the present study was to conduct a comprehensive analysis on floral diversity of tea germplasm in Sri Lanka: (1) to determine the nature and extent of genetic diversity of the tea germplasm and (2) to categorize accessions into major taxa.

\section{Material and Methods}

2.1. Experimental Location and Plant Materials. A total of 89 accessions (i.e., 15\% of the total collection) including exotic origins, estate selections, improved cultivars, unadapted accessions, and other important Camellia spp. representing the total diversity of the Sri Lankan germplasm were selected for the study. While selecting accessions, diversity tree of tea germplasm in Sri Lanka as described by [4] was followed. Accessions were selected to represent each branch of the diversity tree and number of accessions from a branch was selected based on the total available. List of accessions selected for the study is given in Table 1.

All planting materials are maintained as a living collection at the field gene bank at the Tea Research Institute of Sri Lanka, Talawakelle, Sri Lanka (field number 09, St. Coombs Estate; located Lat 6.94N, Long 80.66E, altitude 1256 amsl). The plants are of the same age and have been maintained under similar growth conditions.

2.2. Data Collection. The study was carried out during peak flowering period starting from January to April in 2012, 2013, and 2014. Ten freshly bloomed flowers and ten flower buds were collected from each accession between 9.00 and 10.00 a.m. from three free growing tea bushes. Measurements were repeated three times during the three years' period. Flower buds were collected just before blooming and flowers bloomed on the same day they were collected for the study. Experiment was conducted as a CRD.

The flowers were studied in detail. Thirteen quantitative floral traits, bud length and width, corolla diameter, total number of petals and sepals, number of whorls of sepals and petals, petal length and width, style length, style column length, style arm length, and number of style arms, were recorded. The three qualitative floral traits studied together with the character states are given in the Table 2 . The character ovary pubescence was observed under the low power of a stereo microscope and rated as density per microscopic field.

All traits were measured as per the IPGRI [22] and UPOV [23] guidelines as described below.

Bud length and width: length and width of 10 flower buds were measured using a venire caliper and average measurement was taken; diameter of corolla: average diameter of 10 freshly bloomed flowers was taken; number of petals and sepals: petals and sepals of 10 freshly bloomed flowers were counted manually; petal length and width: length and width of petals were measured using a venire caliper; three pistil traits, namely, style length, style column length, and style arm length, were measured using a Vernier caliper. Number of style arms, total number of sepals, total number of petals, and number of sepal and petal whorls of 10 freshly bloomed flowers were counted manually.

2.3. Data Analysis. The mean values for 13 quantitative traits were used for statistical analysis and descriptive statistics parameters were generated for each trait. Data collected among different years were analyzed separately and there was no significant difference among years. Hence, average data were used for further analysis. Data were subjected to analysis of variance and mean separation was done for each trait to investigate variations among three tea taxa. Thirteen quantitative traits were correlated among each other and subjected to Principle Component Analysis (PCA) for developing new variables. In order to reveal the relationships among germplasm accessions, a dendrogram was constructed 
TABLE 1: List of accessions selected for the study and their pedigree.

\begin{tabular}{|c|c|c|}
\hline Number & Accession & Pedigree/origin \\
\hline 1 & MT 18 & Estate selection from Balangoda Est. (WM1) \\
\hline 2 & DG 39 & Estate selection from Balangoda Est. (WM3) \\
\hline 3 & DG 7 & Estate selection from Balangoda Est. (WM3) \\
\hline 4 & $\mathrm{CV} 4 / \mathrm{B} 1$ & $\begin{array}{l}\text { Estate selection from Cannaverella Est. } \\
\text { (IU3) }\end{array}$ \\
\hline 5 & $\mathrm{CH} 13$ & Estate selection from Craighead Est. (WM2) \\
\hline 6 & DK 24 & $\begin{array}{l}\text { Estate selection from Diyanillakelle Est. } \\
\text { (WU2) }\end{array}$ \\
\hline 7 & $\mathrm{DN}$ & Estate selection from Dayagama Est. (WU2) \\
\hline 8 & DEL 40 & Estate selection from Delta Est. (WU2) \\
\hline 9 & DT 1 & Estate selection from Drayton Est. (WU1) \\
\hline 10 & DT 95 & Estate selection from Drayton Est. (WU1) \\
\hline 11 & DUN 7 & Estate selection from Dunsinane Est. (WU2) \\
\hline 12 & H $1 / 58$ & Estate selection from Hulandawa Est. (WL1) \\
\hline 13 & HS $10 / \mathrm{A}$ & Estate selection from Hethersett Est. (WU3) \\
\hline 14 & K 145 & Estate selection from Kirkoswald Est. (WU1) \\
\hline 15 & MO 241 & Estate selection from Mooloya Est. (WM2) \\
\hline 16 & NAY 3 & Estate selection from Nayabedda Est. (IU3) \\
\hline 17 & NL $8 / 3$ & Estate selection from Neluwa Est. (IU3) \\
\hline 18 & N 2 & Estate selection from Norwood Est. (WU1) \\
\hline 19 & PK 2 & Estate selection from Park Est. (WU3) \\
\hline 20 & PLLG2 & Estate selection from Poonagala Est. (IU3) \\
\hline 21 & PO 26 & Estate selection from Poronuwa Est. (WM1) \\
\hline 22 & QT 4/4 & Estate selection from Queenstown Est. (IU3) \\
\hline 23 & B 275 & Estate selection from Ragala Est. (IU2) \\
\hline 24 & S 106 & Estate selection from Sirikandura Est. (WL1) \\
\hline 25 & TRI 2142 & Estate selection from St. Coombs Est. (WU1) \\
\hline 26 & TRI 2016 & Estate selection from St. Coombs Est. (WU1) \\
\hline 27 & TRI 1294 & Estate selection from St. Coombs Est. (WU1) \\
\hline 28 & TRI 3011 & Estate selection from St. Coombs Est. (WU1) \\
\hline 29 & TRI 26 & Estate selection from St. Coombs Est. (WU1) \\
\hline 30 & TRI 1114 & Estate selection from St. Coombs Est. (WU1) \\
\hline 31 & CY 9 & Estate selection from Tangakelle Est. (WU1) \\
\hline 32 & TC 10 & Estate selection from Tillicoultry Est. (WU2) \\
\hline 33 & WT26 & Estate selection from Waltrim Est. (WU3) \\
\hline 34 & W 3 & Estate selection from Wootton Est. (WU2) \\
\hline 35 & TRI 777 & $\begin{array}{c}\text { Introduction from Shan Cho Long } 777 \\
(1937)\end{array}$ \\
\hline 36 & TRI 2043 & $\begin{array}{c}\text { Introduction from Shan Bang Sang } 777 \\
(1937)\end{array}$ \\
\hline 37 & ASM 4/10 & $\begin{array}{l}\text { Introduction from India (ASM 4/10 seed), } \\
\qquad 1938\end{array}$ \\
\hline 38 & TRI 2023 & $\begin{array}{l}\text { Introduction from India (ASM 4/10 seed), } \\
\qquad 1938\end{array}$ \\
\hline 39 & TRI 2024 & $\begin{array}{l}\text { Introduction from India (ASM 4/10 seed), } \\
\qquad 1938\end{array}$ \\
\hline 40 & TRI 2025 & $\begin{array}{l}\text { Introduction from India (ASM 4/10 seed), } \\
1938\end{array}$ \\
\hline 41 & TRI 2026 & $\begin{array}{l}\text { Introduction from India (ASM 4/10 seed), } \\
1938\end{array}$ \\
\hline 42 & TRI $62 / 5$ & $\begin{array}{l}\text { Introduction from India (ASM 4/10 seed), } \\
\qquad 1958\end{array}$ \\
\hline 43 & TRI $62 / 9$ & $\begin{array}{l}\text { Introduction from India (ASM 4/10 seed), } \\
\qquad 1958\end{array}$ \\
\hline 44 & TRI 3047 & Introduction from India (ASM 4/10 seed) \\
\hline 45 & TRI 3052 & Introduction from India (ASM 4/10 seed) \\
\hline 46 & TRI 3055 & Introduction from India (ASM 4/10 seed) \\
\hline 47 & Yabukital & Introduction from Japan (seed), 1998 \\
\hline 48 & Yabukita2 & Introduction from Japan (seed), 1998 \\
\hline 49 & Yabukita3 & Introduction from Japan (seed), 1998 \\
\hline
\end{tabular}

TABLE 1: Continued.

\begin{tabular}{|c|c|c|}
\hline Number & Accession & Pedigree/origin \\
\hline 50 & Yabukita4 & Introduction from Japan (seed), 1998 \\
\hline 51 & Yabukita5 & Introduction from Japan (seed), 1998 \\
\hline 52 & Yabukita6 & Introduction from Japan (seed), 1998 \\
\hline 53 & PBGT55 & Introduction from Korea (seed), 2000 \\
\hline 54 & PBGT53 & Introduction from Korea (seed), 2000 \\
\hline 55 & PBGT48 & Introduction from Korea (seed), 2000 \\
\hline 56 & PBGT73 & Introduction from Korea (seed), 2000 \\
\hline 57 & PBGT12 & Introduction from Korea (seed), 2000 \\
\hline 58 & PBGT49 & Introduction from Korea (seed), 2000 \\
\hline 59 & PBGT60 & Introduction from Korea (seed), 2000 \\
\hline 60 & PBGT67 & Introduction from Korea (seed), 2000 \\
\hline 61 & PBGT61 & Introduction from Korea (seed), 2000 \\
\hline 62 & PBGT41 & Introduction from Korea (seed), 2000 \\
\hline 63 & TRI 3016 & ASM 4/10× DT 95 \\
\hline 64 & TRI 3019 & ASM 4/10 × DT 95 \\
\hline 65 & TRI 3017 & ASM 4/10 × DT 95 \\
\hline 66 & TRI 4052 & CY $9 \times$ ASM 4/10 \\
\hline 67 & TRI 4053 & $\mathrm{CY} 9 \times \mathrm{ASM} 4 / 10$ \\
\hline 68 & TRI 4049 & $\mathrm{CY} 9 \times \mathrm{ASM} 4 / 10$ \\
\hline 69 & TRI 4067 & CY $9 \times$ NAY 3 \\
\hline 70 & TRI 4068 & CY $9 \times$ NAY 3 \\
\hline 71 & TRI 4076 & $\mathrm{~N} 2 \times \mathrm{N} 2$ \\
\hline 72 & TRI 4078 & $\mathrm{~N} 2 \times \mathrm{N} 2$ \\
\hline 73 & TRI 4079 & $\mathrm{~N} 2 \times \mathrm{N} 2$ \\
\hline 74 & TRI 4061 & TRI $2020 \times$ TRI 2023 \\
\hline 75 & TRI 3022 & TRI $2023 \times$ TRI 2026 \\
\hline 76 & TRI 4085 & TRI $2024 \times$ N2 \\
\hline 77 & TRI 4071 & TRI $2024 \times$ N2 \\
\hline 78 & TRI 3018 & TRI $2024 \times$ TRI 1114 \\
\hline 79 & TRI 3026 & TRI $2024 \times$ TRI 1114 \\
\hline 80 & TRI 3036 & TRI $2024 \times$ TRI 777 \\
\hline 81 & TRI 3041 & ASM 4/10 OP \\
\hline 82 & TRI 3013 & TRI 2024 OP \\
\hline 83 & TRI 3072 & TRI 2025 OP \\
\hline 84 & TRI 3014 & TRI 2025 OP \\
\hline 85 & TRI 3073 & TRI 2025 OP \\
\hline 86 & TRI 3015 & TRI 2026 OP \\
\hline 87 & TRI 3050 & TRI 3011 OP \\
\hline 88 & VHMOR & Unknown origin \\
\hline 89 & INTRI6 & Unknown origin \\
\hline
\end{tabular}

using major Principle Components. The accessions were grouped by average linkage cluster analysis.

All the above statistical analyses were performed by using SAS 9.1 for Windows software [24] and PAST 3.

\section{Results and Discussion}

3.1. Morphological Diversity of the Tea Germplasm Based on Floral Traits. Distribution of variation of 13 quantitative 
TABLE 2: List of qualitative traits used for the study.

\begin{tabular}{ll}
\hline Character & Character state \\
\hline Ovary pubescence & $\begin{array}{l}\text { Densely hairy, slightly (intermediate), } \\
\text { sparsely } \\
\text { Stigma position }\end{array}$ \\
$\begin{array}{l}\text { Below stamen whorl, same level as the } \\
\text { stamen whorl, above the stamen whorl } \\
\text { Geniculate, free for greater part of their } \\
\text { length } \\
\text { Split pattern of style } \\
\text { Ascending, free for about half their length } \\
\text { United, united for greater part of their } \\
\text { length }\end{array}$ \\
\hline
\end{tabular}

TABLE 3: Descriptive statistics of morphological traits of tea germplasm.

\begin{tabular}{lcccc}
\hline Trait & Min & Max & Mean & CV\% \\
\hline Bud length (mm) & 9.91 & 16.03 & 12.97 & 10.17 \\
$\begin{array}{l}\text { Bud width (mm) } \\
\begin{array}{l}\text { Corolla diameter } \\
\text { (mm) }\end{array}\end{array}$ & 12.05 & 15.18 & 11.48 & 10.37 \\
$\begin{array}{l}\text { Petal length (mm) } \\
\text { Petal width (mm) }\end{array}$ & 14.19 & 24.00 & 17.56 & 11.23 \\
$\begin{array}{l}\text { Total number of } \\
\text { sepals }\end{array}$ & 9.72 & 54.06 & 14.38 & 33.81 \\
$\begin{array}{l}\text { Total number of } \\
\text { petals }\end{array}$ & 4 & 7 & 5.20 & 8.78 \\
$\begin{array}{l}\text { Number of whorls of } \\
\text { sepals }\end{array}$ & 2 & 3 & 2.06 & 11.26 \\
$\begin{array}{l}\text { Number of whorls of } \\
\text { petals }\end{array}$ & 2 & 3 & 2.73 & 16.35 \\
$\begin{array}{l}\text { Number of style arms } \\
\text { Style length (mm) }\end{array}$ & 3 & 4 & 3.13 & 10.96 \\
$\begin{array}{l}\text { Style column length } \\
\text { (mm) }\end{array}$ & 0 & 10.59 & 6.72 & 38.83 \\
$\begin{array}{l}\text { Style arm lengths } \\
\text { (mm) }\end{array}$ & 1.11 & 10.23 & 3.99 & 57.70 \\
\hline
\end{tabular}

Min $=$ minimum value $\max =$ maximum value $C \mathrm{CV}=$ coefficient of variance.

morphological traits measured among germplasm accessions is shown in Table 3.

As illustrated by descriptive statistics, among the traits, petal width, style column length, and style arm length showed higher variation than the other traits having high coefficient of variance $(\mathrm{CV})$ values. Conversely, traits, namely, total number of sepals, bud length, and width, petal length and number of whorls of sepals recorded low CV values indicating less diversity among the germplasm accessions.

The smallest bud length was observed in Yabukita3 (9.91 $\mathrm{mm}$ ) seedling and the smallest bud width was recorded in TRI $4067(8.05 \mathrm{~mm})$ cultivar. The largest bud length of $16.03 \mathrm{~mm}$ value was recorded in TRI 3014 cultivar and the largest bud width of $15.18 \mathrm{~mm}$ value was found in TRI 2043 cultivar.

The size of the tea flower varies extensively among different accessions studied (Figure 1) and could be categorized as small, medium, and large in size. The largest flowers were

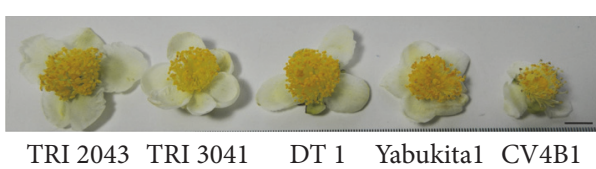

FIGURE 1: Variation of flower size (corolla diameter) among different accessions $($ bar $=1 \mathrm{~cm})$.

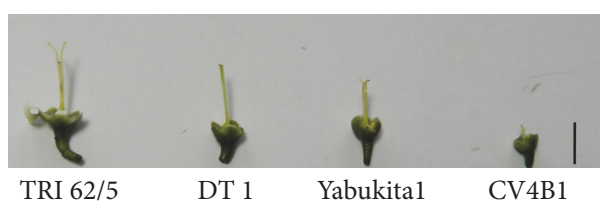

FIGURE 2: Variation of style length among different accessions (bar $=1 \mathrm{~cm})$.

observed in cultivar TRI 3016 with a corolla diameter of $48.21 \mathrm{~mm}$ and the smallest flowers were observed in estate cultivar PO 26 with a corolla diameter of $23.33 \mathrm{~mm}$.

Minimum and maximum petal lengths were observed in the accession QT 4/4 and cultivar TRI 2043, respectively, and minimum and maximum petal widths were recorded in estate cultivar DUN 7 and cultivar TRI 3014. Among the 89 accessions studied, flowers with variable number of petals and sepals were observed. Number of petals varied from 5 to 12 and number of sepals varied from 4 to 7 . Number of whorls of sepals and petals were 2-3 in all accessions.

It was observed that pistil related morphological traits were highly varied in the tea germplasm. Out of the 89 accessions studied, 77 accessions had three style arms which is common in tea and 12 had four style arms. Also, style column length (Figure 2) and style arm lengths varied among accessions having high CV values of $39 \%$ and $58 \%$, respectively. A previous study conducted using 27 accessions from Sri Lankan tea germplasm also revealed that variations of the germplasm could be explained by three pistil traits: number of arms in the style, style column length, and style arm lengths to the greatest extent [21]. Hence, results from the current study are in agreement with those findings.

Stigma position relative to stamens is another parameter that varied among accessions. As explained in Figure 3, 64\% of the accessions possess stigma and stamen at the same level and $29 \%$ of the accessions are having stigma position above stamen level. However, no correlation was observed among stigma position relative to stamens and major tea taxa.

3.2. Correlation between Floral Traits. Correlation analysis among 13 traits revealed positive and negative correlations among different floral morphological traits as shown in Table 4 . Bud length was positively correlated with bud width, corolla diameter, and petal length while bud width showed positive correlation with petal length and corolla diameter. There was a high correlation between corolla diameter and petal width. It was interesting to note that pistil traits are correlated with each other as well as with some flower traits. Style length showed a positive correlation with style column length. However, style column length showed a 


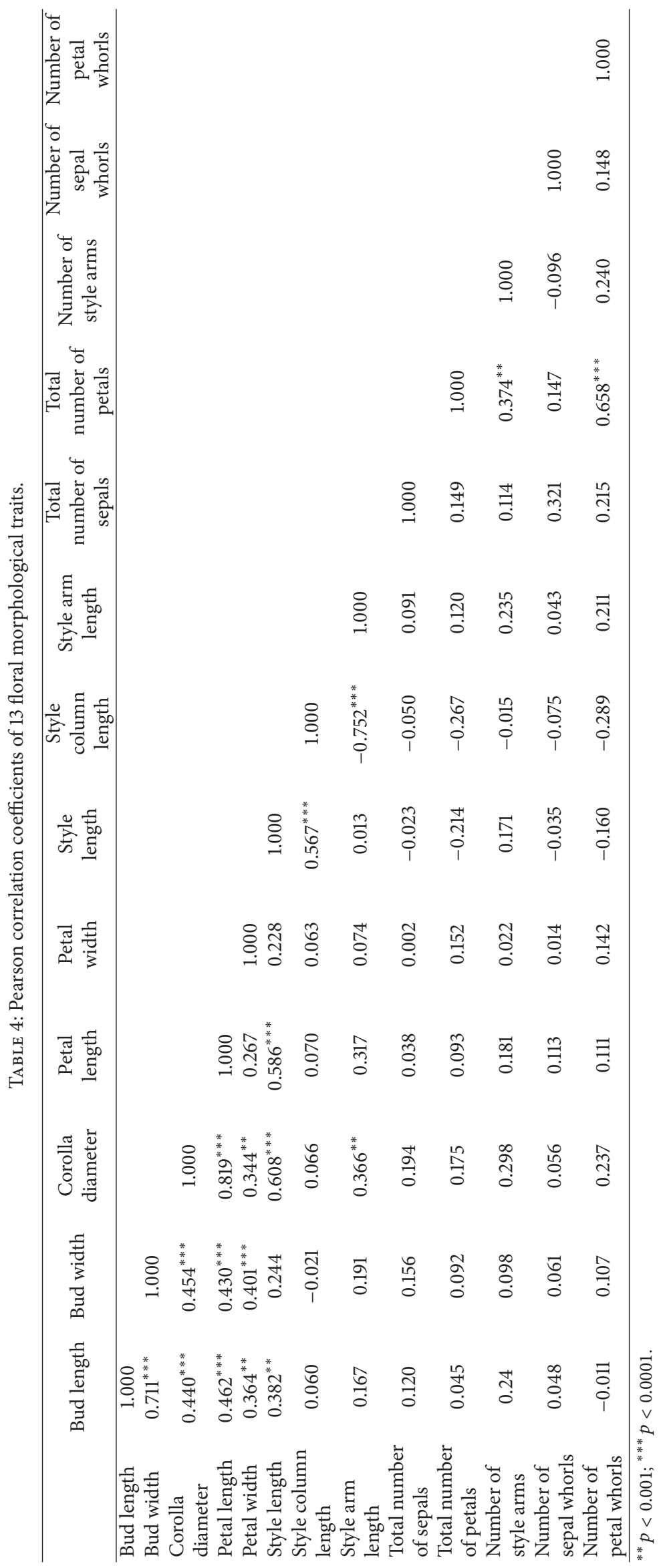




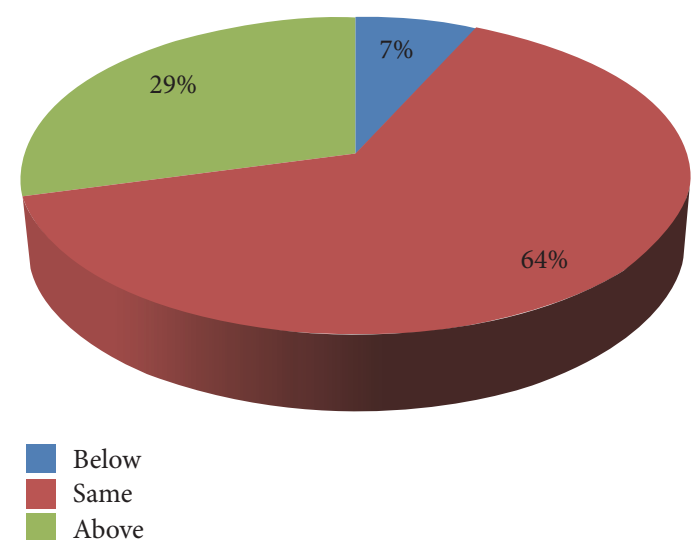

FIGURE 3: Variation of stigma position relative to stamens in the germplasm.

negative correlation with style arm length. A previous study also reported a negative correlation between style column length and style arm length [21]. Style length was positively correlated with corolla diameter and petal length. Also, a positive correlation was observed between number of style arms and total number of petals. As pistil traits are important in taxonomic classification in tea, it is worthwhile studying these relationships in depth. Therefore, it may be useful to identify few parameters from the study to combine with pistil traits to develop a more reliable methodology to distinguish individual accessions into different archetypes especially when extensive hybridization takes place among tea taxa.

\subsection{Principle Component Analysis (PCA) of Floral Traits} and Grouping of Accessions. When 13 traits were subjected to PCA, around $76 \%$ of the variability in the floral traits was described by first five Principle Components (PCs). As indicated in Table 5, first PC was loaded with two flower traits, corolla diameter, and petal length whereas the loading of the second and third PCs was contributed by pistil traits, namely, style length, style column length, and style arm length. It has been reported that number of style arms contributed to variations [21]; however, in the present study loadings of the fourth PC were affected by number of style arms.

Resultant dendrogram generated by average linkage cluster analysis based on first five PCs is shown in Figure 4. The accessions exhibited large variations and estimated average distance between clusters varied from 0.03 between most similar accessions W3 and TRI 4053 to 1.9 between TRI 3014 and rest of the 88 accessions.

The dendrogram divided accessions into five groups.

Cultivar TRI 3014 separated from other 88 accessions at an average distance of 1.896 being highly discriminated from all others. TRI 3014 is a recommended tea cultivar for mid country wet zone and low elevations of Sri Lanka [25]. TRI 3014 recorded the largest bud width and maximum petal length during the floral trait examination.

The second cluster separated from other accessions with an average distance of 1.46 and two recommended cultivars TRI 2043 and TRI 3016 were included in this group. TRI
TABLE 5: Eigenvalues, individual, and cumulative percentage of variation explained by the first five principal components loadings of the 13 quantitative characteristics.

\begin{tabular}{|c|c|c|c|c|c|}
\hline Character & PC1 & PC2 & PC3 & PC4 & PC5 \\
\hline Bud length & 0.38 & -0.12 & -0.08 & 0.17 & -0.29 \\
\hline Bud width & 0.37 & -0.04 & -0.08 & 0.27 & -0.39 \\
\hline $\begin{array}{l}\text { Corolla } \\
\text { diameter }\end{array}$ & 0.46 & -0.05 & -0.13 & -.09 & 0.24 \\
\hline Petal length & 0.43 & -0.11 & -0.10 & -0.04 & 0.25 \\
\hline Petal width & 0.27 & -0.05 & 0.04 & 0.08 & -0.54 \\
\hline Style length & 0.31 & -0.40 & 0.05 & -0.15 & 0.28 \\
\hline $\begin{array}{l}\text { Style column } \\
\text { length }\end{array}$ & 0.00 & -0.52 & 0.46 & -0.12 & 0.01 \\
\hline $\begin{array}{l}\text { Style arm } \\
\text { length }\end{array}$ & 0.22 & 0.34 & -0.53 & 0.01 & 0.24 \\
\hline $\begin{array}{l}\text { Number of } \\
\text { style arms }\end{array}$ & 0.21 & 0.15 & 0.14 & -0.51 & 0.14 \\
\hline $\begin{array}{l}\text { Total number } \\
\text { of sepals }\end{array}$ & 0.12 & 0.17 & 0.34 & 0.41 & 0.28 \\
\hline $\begin{array}{l}\text { Total number } \\
\text { of petals }\end{array}$ & 0.15 & 0.42 & 0.38 & -0.25 & -0.18 \\
\hline $\begin{array}{l}\text { Number of } \\
\text { sepal whorls }\end{array}$ & 0.07 & 0.14 & 0.30 & 0.58 & 0.28 \\
\hline $\begin{array}{l}\text { Number of } \\
\text { petal whorls }\end{array}$ & 0.16 & 0.42 & 0.33 & -0.17 & -0.09 \\
\hline Eigen value & 3.61 & 2.47 & 1.40 & 1.26 & 1.12 \\
\hline Difference & 1.14 & 1.06 & 0.14 & 0.14 & \\
\hline $\begin{array}{l}\text { Variance } \\
\text { explained (\%) }\end{array}$ & 27.75 & 18.94 & 10.78 & 9.68 & 8.62 \\
\hline $\begin{array}{l}\text { Variance } \\
\text { cumulative } \\
(\%)\end{array}$ & 27.75 & 46.69 & 57.47 & 67.15 & 75.77 \\
\hline
\end{tabular}

2043 is a unique cultivar recommended for silver tip production [25], characteristic with anthocyanin pigmentation and densely arranged pubescence in lower leaf epidermis and buds [2]. A previous study conducted to characterize tea germplasm using vegetative morphological traits reported that TRI 2043 was separated from all other accessions [20]. In the present study, TRI 2043 recorded the largest bud width and maximum petal length among the germplasm accessions. TRI 3016 recorded the largest corolla diameter.

The third cluster with five accessions separated at an average distance of 1.25 from other 81 accessions. The five accessions included two estate selections CY 9 and DG 7 and one recommended cultivar TRI 3055, a recent introduction from Korea PBGT41 and INTRI6 which is an accession with unknown origin. All these accessions belong to Cambod type as shown in Table 6.

There are nine accessions grouped in the fourth cluster which separated at an average distance of 1.13 from the rest. Two estate selections B 275 and NAY 3, one recommended cultivar TRI 4067, and six exotic accessions introduced from Korea (PBGT 48, PBGT 49, PBGT53, PBGT55, PBGT67, and PBGT73) were found in this group. The most interesting feature of the group is that it contains all nine accessions 


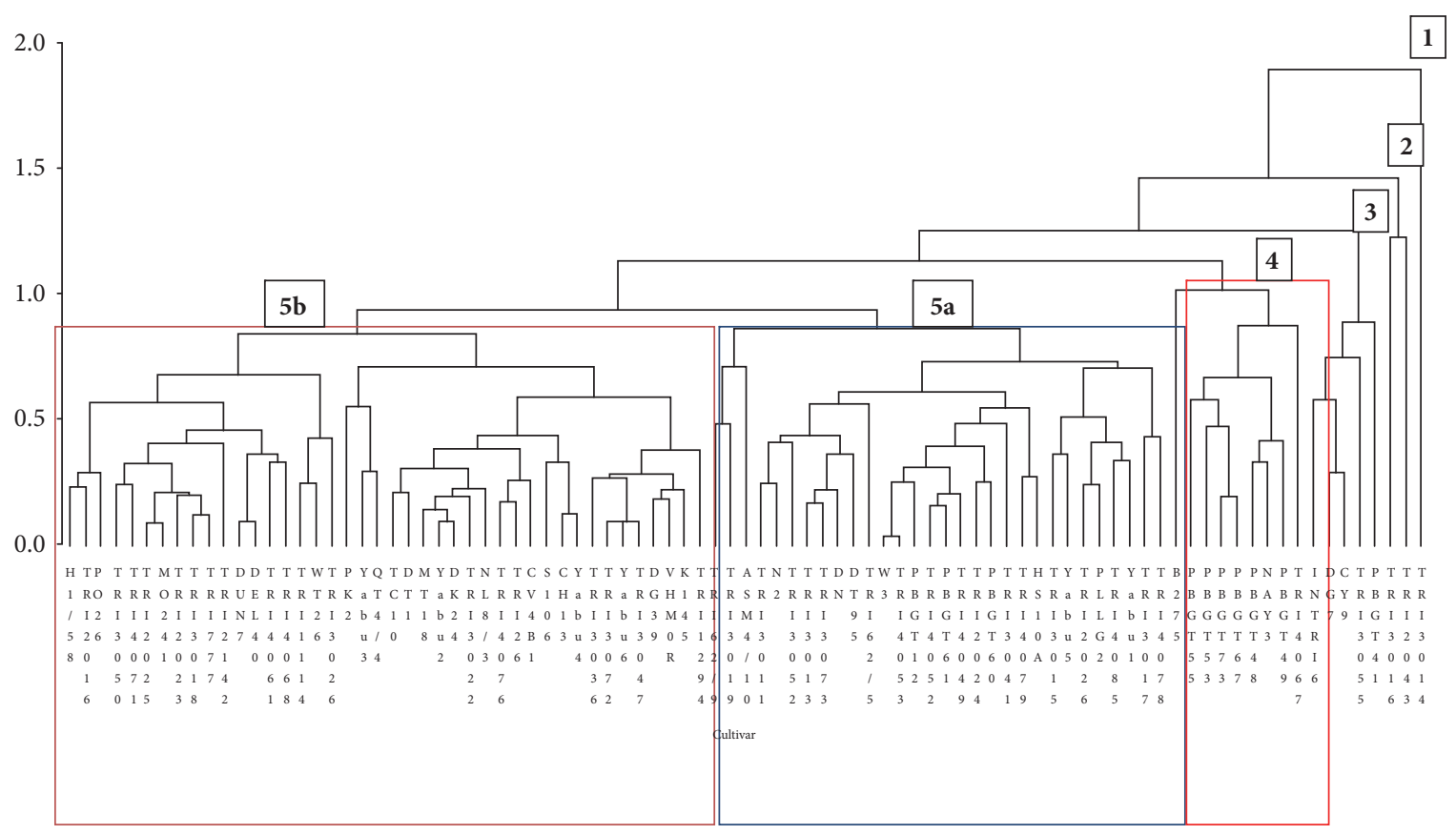

FIGURE 4: Dendrogram of average linkage cluster analysis based on 13 morphological characteristics.

belonging to China type. As indicated in Table 6, out of the 11 China type accessions used in the study, nine were grouped together based on the overall variation in floral traits.

The fifth cluster has two subclusters $5 \mathrm{a}$ and $5 \mathrm{~b}$ with 30 and 42 accessions, respectively. Both subclusters have mixture of accessions sharing variable floral features. Thirteen Assam type accessions (Table 6) are grouped in subcluster 5b.

The score plot of the first two PCs is shown in Figure 5. It has been found that cultivars TRI 4067, TRI 2043, NAY 3, and DUN 7 are extreme observations along the PC1. Also, two cultivars INTRI 6 and TRI 2026 were found to be different along the PC2. The information present in the loadings is displayed in Figure 6. All 13 variables are represented in the biplot by a vector and the direction and length of the vector indicate how each variable contributes to PC1 and PC2. The PC1 has positive coefficient for the variables bud length and width, diameter of corolla, style length, style column length, and petal length and width. The largest coefficients in the PC1 are two pistil traits style column length and style arm length. The PC2 has positive coefficients for 10 traits except style column length, petal length, and total number of style arms. The largest coefficients in the PC2 are bud length and diameter of corolla.

3.4. Genetic Structure of Sri Lankan Tea Germplasm Based on Floral Traits. Split pattern of style was used to differentiate between variety and subspecies levels within C. sinensis [7]. According to his classification, as shown in Figure 7, China types (C. sinensis var. sinensis) are having geniculate styles (free for greater part of their length) and Cambod types ( $C$. sinensis ssp. lasiocalyx) are ascending type in nature (free for about half their length). Wight [7] further stated that styles

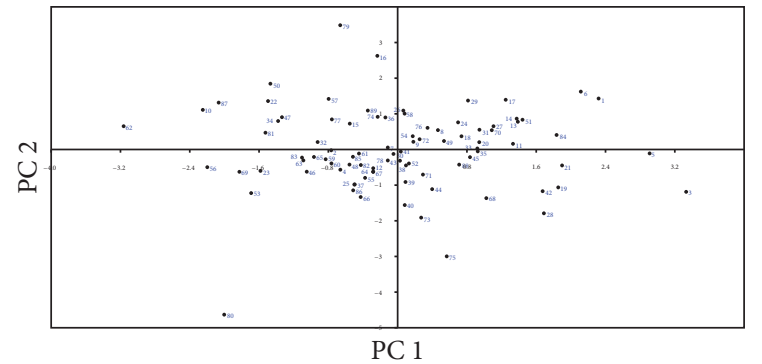

FIGURE 5: PCA score plot of 89 accessions. $(1=\mathrm{H1} / 58,2=$ TRI62/9, 3 = INTRI6, 4 = DG7, 5 = TRI3055, 6 = ASM4/10, 7 = PK2, $8=$ TRI3011, $9=\mathrm{W} 3,10=$ TRI3050, $11=$ TRI4053, $12=$ TRI4052, $13=$ TRI3015, 14 $=$ TRI3013, $15=$ TRI2025, $16=$ DUN7, $17=$ TC10, $18=$ TRI62 $/ 5,19=$ CY9, 20 = B275, 21 = DT95, 22 = TRI2024, 23 = S106, 24 = DEL40, 25 = TRI4049, 26 = TRI4071, $27=$ TRI4079, $28=$ TRI3019, $29=$ TRI2023, $30=$ TRI2026, $31=$ DN, $32=$ TRI3036, $33=$ TRI3052, $34=$ TRI3072, $35=$ TRI3014, $36=$ TRI3018, $37=$ TRI4085, $38=$ TRI4076, $39=$ TRI4061, 40 = MT18, 41 = TRI3017, 42 = TRI3016, 43 = PO26, $44=\mathrm{CV} 4 \mathrm{~B} 1,45=\mathrm{DT} 1,46=\mathrm{CH} 13,47=\mathrm{TRI} 2142,48=\mathrm{DG} 39,49=$ HS1OA, 50 = TRI2016, 51 = TRI1114, 52 = Yabukital, 53 = Yabukita3, $54=$ Yabukita5, 55 = Yabukita4, $56=$ TRI1294, $57=$ MO241, $58=$ TRI777, $59=\mathrm{NL} 8 / 3,60=\mathrm{N} 2,61=$ TRI3022, $62=$ TRI3026, $63=$ TRI3047, $64=$ TRI4068, $65=$ PBGT55, $66=$ PBGT53, $67=$ PBGT48, $68=$ PBGT73, $69=$ PBGT12, $70=$ TRI3073, $71=$ PBGT49, $72=$ PBGT60, 73 = PBGT67, $74=$ PLLG2, $75=$ NAY3, $76=$ WT26, 77 $=$ VHMOR, $78=$ K145, $79=$ TRI2043, $80=$ TRI4067, $81=$ TRI4078, $82=$ TRI26, $83=$ PBGT61, $84=$ PBGT41, $85=$ TRI3041, $86=$ QT4 $/ 4$, 87 = Yabukita6, $88=$ Yabukita2, and $89=$ DK24.)

of Assam types (C. sinensis var. assamica) are characteristic with united style (united for greater part of their length). Classification by Wight [7] on major tea taxa is generally 
TABLE 6: Grouping of accessions/cultivars based on character split pattern of style.

\begin{tabular}{|c|c|c|c|}
\hline \multicolumn{2}{|c|}{ Cambod type } & Assam type & China type \\
\hline \multicolumn{4}{|c|}{ Estate selections } \\
\hline CY 9 & TRI 2016 & $\mathrm{CH} 13$ & B 275 \\
\hline DEL 40 & TRI 26 & CV4B1 & NAY 3 \\
\hline DG 39 & TRI 3011 & N 2 & \\
\hline DG 7 & W 3 & NL $8 / 3$ & \\
\hline DK 24 & WT 26 & PO 26 & \\
\hline $\mathrm{DN}$ & MO 241 & QT 4/4 & \\
\hline DT 1 & MT 18 & S 106 & \\
\hline DT 95 & PK 2 & TC 10 & \\
\hline DUN 7 & PLLG 2 & & \\
\hline H 1/58 & TRI 1114 & & \\
\hline HS1OA & TRI 1294 & & \\
\hline K 145 & TRI 2142 & & \\
\hline \multicolumn{4}{|c|}{ Introductions } \\
\hline TRI 2023 & ASM 4/10 & Yabukita03 & PBGT67 \\
\hline TRI 2024 & PBGT60 & Yabukita04 & PBGT48 \\
\hline TRI 2025 & PBGT61 & Yabukita06 & PBGT49 \\
\hline TRI 2026 & PBGT12 & TRI 777 & PBGT53 \\
\hline TRI 62/5 & PBGT41 & TRI 2043 & PBGT55 \\
\hline Yabukita01 & TRI 3052 & & PBGT73 \\
\hline Yabukita02 & TRI 3055 & & \\
\hline Yabukita05 & TRI 3047 & & \\
\hline \multicolumn{4}{|l|}{ TRI $62 / 9$} \\
\hline \multicolumn{4}{|c|}{ Improved cultivars } \\
\hline TRI 4061 & TRI 3015 & TRI 3013 & TRI 3016 \\
\hline TRI 4068 & TRI 3017 & TRI 3014 & TRI 3019 \\
\hline TRI 4071 & TRI 3022 & TRI 3018 & TRI 4067 \\
\hline TRI 4076 & TRI 3026 & TRI 3036 & \\
\hline TRI 4078 & TRI 3041 & & \\
\hline TRI 4079 & TRI 3073 & & \\
\hline TRI 4085 & TRI 4049 & & \\
\hline TRI 4053 & TRI 4052 & & \\
\hline \multicolumn{4}{|c|}{ Unknown origin } \\
\hline INTRI6 & & VHMOR & \\
\hline
\end{tabular}

accepted and widely adopted globally for identification of genetic structure.

Among the 89 beverage type accessions studied, 60 recorded ascending type styles, 18 reported united styles, and 11 accessions were having geniculate styles. Accordingly, accessions can be categorized into three major groups as indicated in Table 6.

Based on variation in split pattern of stigma, the beverage type accessions of Sri Lankan tea germplasm are predominantly represented by Cambod type (68\%) followed by Assam type (20\%) and China types are poorly represented (Figure 8). As per the records, during the early stages of the tea industry in Sri Lanka, seeds mainly of China type were (during 1824-1833) introduced for mass cultivation and the exercise was a complete failure as seeds were unable to flourish in the island [26]. A large consignment of Chinese tea seeds

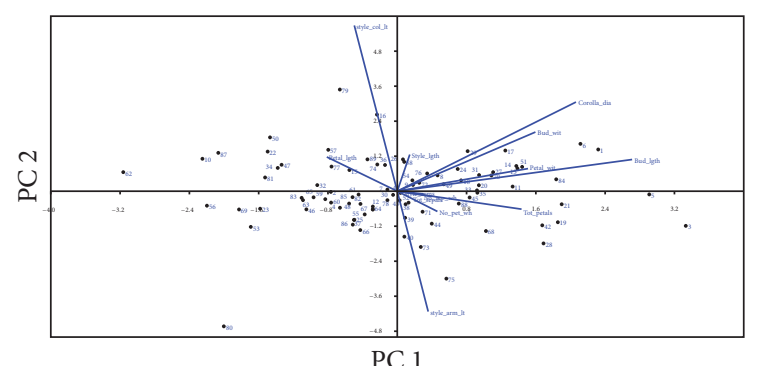

FIgURE 6: PCA loading plot of 13 variables along PC1 and PC2.

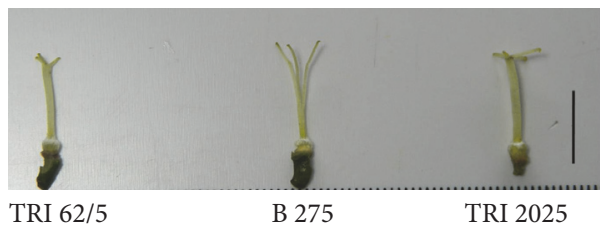

FIGURE 7: Variation in split pattern of stigma in accessions, TRI62/5 (United), B275 (Geniculate), and TRI2025 (Ascending) representing Assam, China, and Cambod, respectively $(\mathrm{bar}=1 \mathrm{~cm})$.

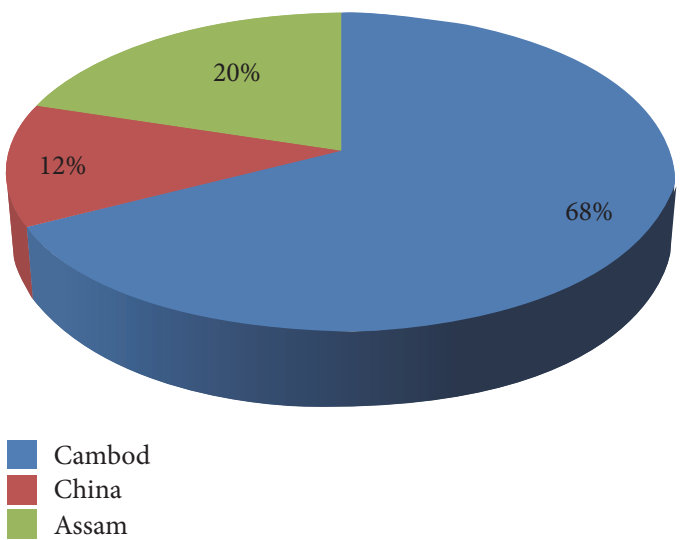

FIGURE 8: Percentages of accessions that fall into major tea taxa available in the tea germplasm.

was introduced into various regions of Northeast India, and widespread spontaneous hybridization took place with the endemic gene pool of C. sinensis var. assamica [26, 27]. These hybrids exhibited a significant polymorphism and were better adapted to colonize the new habitats. This may be the reason for availability of a large number of Cambod type accessions in Sri Lankan tea germplasm compared to Assam and China type.

These results are in agreement with previous findings, based on a coefficient of parentage (COP) analysis in commercial tea cultivars in Sri Lanka, where it was reported that ASM 4/10 and CY 9 were the main ancestral lines that contributed to the cultivated tea gene pool [28]. Both these cultivars show more affinity towards Cambod origin (Table 6). 
TABLE 7: Summary of floral characters of major tea taxa.

\begin{tabular}{|c|c|c|c|c|c|c|}
\hline \multirow{3}{*}{ Floral characters } & \multicolumn{6}{|c|}{ Statistical parameters } \\
\hline & \multicolumn{2}{|c|}{ China type } & \multicolumn{2}{|c|}{ Cambod type } & \multicolumn{2}{|c|}{ Assam type } \\
\hline & Range & Mean & Range & Mean & Range & Mean \\
\hline Bud length (mm) & $11.03-15.62$ & 13.08 & $10.68-15.74$ & 13.10 & $9.91-16.03$ & 12.46 \\
\hline Bud width (mm) & $8.05-12.95$ & 11.64 & $8.61-13.87$ & 11.57 & $9.24-15.18$ & 11.07 \\
\hline Corolla diameter (mm) & $26.68-48.21$ & 32.74 & $12.56-38.72$ & 32.43 & $23.33-44.49$ & 29.76 \\
\hline Petal length (mm) & $14.26-20.46$ & 17.28 & $14.58-22.80$ & 17.90 & $10.10-54.06$ & 15.09 \\
\hline Petal width $(\mathrm{mm})$ & $10.62-17.33$ & 13.88 & $9.72-24.01$ & 14.26 & $8.16-12.75$ & 9.99 \\
\hline Total number of sepals & $5-6$ & 5.27 & $4-7$ & 5.22 & $5-6$ & 5.11 \\
\hline Total number of petals & $6-10$ & 7.64 & $5-12$ & 7.47 & $5-9$ & 6.94 \\
\hline Total number of style arms & $3-4$ & 3.18 & $3-4$ & 3.17 & 3 & 3 \\
\hline Number of whorls of sepals & 2 & 2 & $2-3$ & 2.10 & 2 & 2 \\
\hline Number of whorls of petals & $2-3$ & 2.90 & $2-3$ & 2.72 & $2-3$ & 2.67 \\
\hline Style length $(\mathrm{mm})$ & $3.58-12.90$ & $9.17^{\mathrm{b}}$ & $7.76-14.61$ & $10.85^{\mathrm{a}}$ & $4.81-10.59$ & $8.07^{\mathrm{ab}}$ \\
\hline Style column length (mm) & $0.00-3.33$ & $0.93^{\mathrm{b}}$ & $3.75-10.55$ & $7.42^{\mathrm{a}}$ & $1.11-4.02$ & $2.23^{\mathrm{a}}$ \\
\hline Style arm lengths (mm) & $3.58-10.01$ & $8.25^{\mathrm{a}}$ & $1.80-10.23$ & $4.25^{\mathrm{b}}$ & $1.11-4.02$ & $2.23^{\mathrm{b}}$ \\
\hline Ovary pubescence & \multicolumn{2}{|c|}{ Sparsely to densely hairy } & \multicolumn{2}{|c|}{ Sparsely to densely hairy } & \multicolumn{2}{|c|}{ Slightly to densely hairy } \\
\hline Stigma position & \multicolumn{2}{|c|}{$\begin{array}{c}\text { Below or above or same level as } \\
\text { the stamen whorl }\end{array}$} & \multicolumn{2}{|c|}{$\begin{array}{l}\text { Below or above or same level as } \\
\text { the stamen whorl }\end{array}$} & \multicolumn{2}{|c|}{$\begin{array}{l}\text { Below or above or same level as } \\
\text { the stamen whorl }\end{array}$} \\
\hline Style & \multicolumn{2}{|c|}{ Geniculate } & \multicolumn{2}{|c|}{ Ascending } & \multicolumn{2}{|c|}{ United } \\
\hline
\end{tabular}

Means with the same letter are not significantly different.

An analysis of the distribution of the main tea taxa estate selections, improved cultivars, and introductions in Sri Lankan tea germplasm are given below.

3.4.1. Estate Selections. Estate selections are very vital components in tea germplasm as they adapted from various agroecological regions of the country and have enormous potential in tea crop improvement programmes. Out of the 34 estate selections used in the study, 24 resemble Cambod type and eight showed Assam type pistil characters. Only two estate selections B 275 and NAY 3 belong to China taxa. All six estate selections from St. Coombs Estate, Talawakelle, used for the study showed Cambod type affinity. A previous study conducted using 50 estate selections also revealed that majority of the estate selections in the germplasm are Assam and Cambod types [29]. Therefore, tea germplasm is inadequately represented by China type in estate selections too. Hence, it is necessary to expand future estate selection programmes aiming at selection of accessions related to China taxa [30].

3.4.2. Introductions. The first tea germplasm in Sri Lanka was introduced as tea seeds from India and China during the early stages of the industry and subsequent explorations of exotic germplasm for cultivar development should not be overlooked, as many recommended tea cultivars in use were based on germplasm from introductions [4]. As indicated from the results, a higher percentage of introductions acquired prior to 1960 s (83\%) from India and Indo-China were reported as Cambod types.
On the contrary, results showed that recent introductions from Korea (PBGT accessions) belong to China (60\%) archetype. Inadequate representation of China types in tea germplasm warrants continuation of exploration of germplasm with China characters preferably from exotic origins [30].

3.4.3. Improved Cultivars. Around $72 \%$ of the improved cultivars were categorized as Cambod types. Majority of the improved cultivars were reminiscent of more affinity to Cambod taxa and this may be due to the selection for large leaved characters during cultivar development programme to maintain higher productivity levels over small leaved China types giving low yields. However, to maintain appreciable level of diversity in cultivated genepool, it is of utmost importance to concentrate on acquiring or developing cultivars having China characters aiming to use other desirable traits that are not present in high yielding types.

3.5. Variation of Other Floral Traits among Tea Taxa. Summary of floral traits of major three taxa, Cambod type, Assam type, and China type, is given in Table 7.

Among the floral traits of the three taxa, the pistil traits, namely, style length, style column length, and style arm lengths, showed a significant variation. Highest style length and style column length was recorded in Cambod type accessions and China type accessions had highest style arm length. All other traits did not show significant variations among three taxa.

Among the three qualitative traits used, ovary pubescence and stigma position relative to the stamen whorl did not 


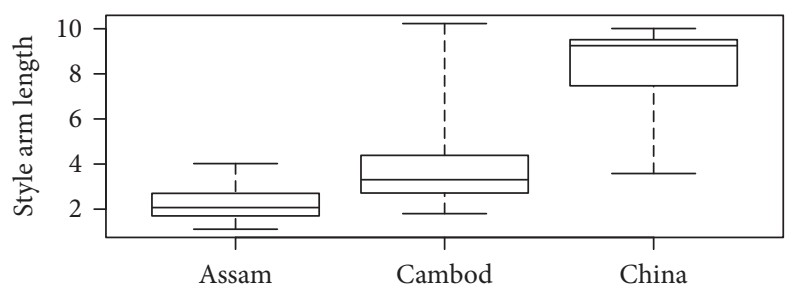

(a) Variation of style arm length among three taxa

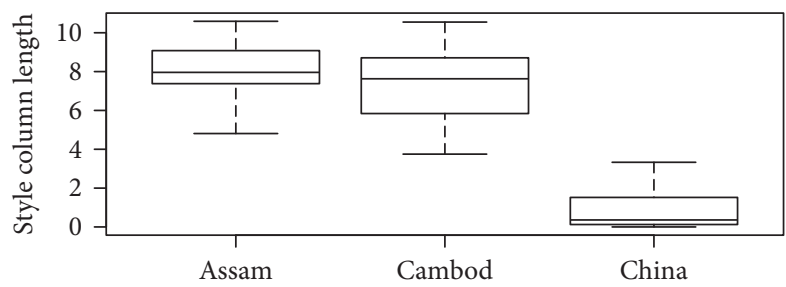

(b) Variation of style column length among three taxa

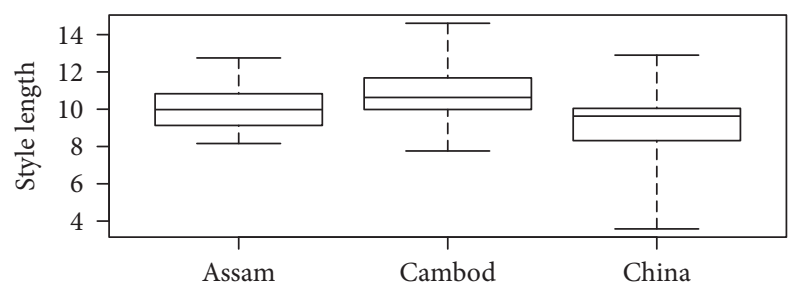

(c) Variation of style length among three taxa

FIGURE 9

show any relationship with three taxa. Hence, these two traits cannot be used to distinguish between three taxa.

Variation of pistil traits among major taxa is shown in Figures 9(a), 9(b), and 9(c). It is clear from these figures that pistil traits are significantly varied among three taxa.

\section{Conclusions}

This is the first comprehensive study to determine the genetic structure of tea germplasm in Sri Lanka using pistil traits and results indicate presence of considerable variation among germplasm accessions. Accessions could be categorized into five different groups based on the diversity of floral traits and it was possible to identify highly discriminating accession such as TRI 3014 based on the grouping pattern. Among the 13 traits, pistil traits are highly variable compared to other traits and they are useful as taxonomic markers in classifying accessions into major tea taxa. Further, grouping pattern of accessions enables separating accessions belonging to China taxa indicating the usefulness of pistil traits in classifying accessions. Overall, 13 floral traits used in the study could be effectively utilized to categorize germplasm accessions in future studies too.

Present study generated valuable information on genetic structure of tea germplasm of Sri Lanka. It was revealed that the Sri Lanka tea germplasm was predominantly represented by Cambod type accessions followed by Assam types. Availability of China type accessions is low. Similar trend can be observed in two major categories of germplasm, estate selections, and improved cultivars indicating selection programmes were more biased towards Cambod and Assam archetypes. On the contrary, recent introductions to the germplasm from Japan and Korea have more affinity towards China types. Hence, the present study identifies gaps in the germplasm collection and information generated can be used for decision making in future germplasm exploration missions. Thus, future exploration missions have to be geared to acquire more China type accessions and it is suggested to concentrate this fact on continuing future estate selection programme. Furthermore, it may be worthwhile developing China hybrids in future crop improvement programmes to enrich the Sri Lankan tea germplasm.

\section{Conflicts of Interest}

The authors declare that there are no conflicts of interest regarding the publication of this paper.

\section{References}

[1] Z. M. Chen and L. Chen, "Delicious and healthy tea: an overview," in Global Tea Breeding-Achievements, Challenges and Perspectives, L. Chen and Z. Apostolides, Eds., pp. 1-11, Springer, Berlin, Germany, 2012.

[2] M. T. K. Gunasekare, M. A. B. Ranatunga, J. H. N. Piyasundara, and J. D. Kottawa-Arachchi, "Tea genetic resources in Sri Lanka: collection, conservation and appraisal," International Journal of Tea Science, vol. 8, no. 3, pp. 51-60, 2012.

[3] M. T. K. Gunasekare, "Applications of molecular markers to the genetic improvement of Camellia sinensis L. (tea) - a review," Journal of Horticultural Science and Biotechnology, vol. 82, no. 2, pp. 161-169, 2007.

[4] M. A. B. Ranatunge and M. T. K. Gunasekare, "Assembling of preliminary core collection of tea (Camellia sinensis (L.) O. Kuntze) genetic resources in Sri Lanka," Plant Genetic Resources Newsletter, no. 155, pp. 41-45, 2008.

[5] M. T. K. Gunasekare, “Tea plant (Camellia sinensis) breeding in Sri Lanka," in Global Tea Breeding-Achivements, Challenges and Perspectives, L. Chen and Z. Apostolides, Eds., pp. 125-176, Springer, Berlin, Germany, 2012.

[6] R. Sealy, A revision of genus Camellia, The Royal Horticultural Society, London, England, 1958.

[7] W. Wight, “Tea classification revised," Current Science, vol. 31, pp. 298-299, 1962.

[8] B. Banerjee, "Botanical classification of tea, in Tea cultivation to consumption," in Chapman Hall publication, K. C. Wilson and and M. N. Clifford, Eds., pp. 555-601, London, 1992.

[9] D. R. Kaplan, “The science of plant morphology: definition, history, and role in modern biology," American Journal of Botany, vol. 88, no. 1-12, pp. 1711-1741, 2001.

[10] L. Martínez, P. Cavagnaro, R. Masuelli, and J. Rodríguez, "Evaluation of diversity among Argentine grapevine (Vitis vinifera L.)varieties using morphological data and AFLP markers," Electronic Journal of Biotechnology, vol. 6, no. 3, pp. 78-87, 2003.

[11] W. Jiang, M. Nitin, B. Jiang, Y. P. Zheng, S. S. Hong, and H. F. Lu, "Floral morphology resolves the taxonomy of Camellia L. (Theaceae) sect. Oleifera and sect. Paracamellia," Bangladesh Journal of Plant Taxonomy, vol. 19, no. 2, pp. 155-165, 2012. 
[12] T. Toyao and Y. Takeda, "Studies on geographical diversity of floral morphology of tea plant (Camellia sinensis (L.) O. Kuntze) using the method of Numerial Taxonomy," Tea Research Journal, no. 87, pp. 39-57, 1999.

[13] J. Chen, P. Wang, Y. Xia, M. Xu, and S. Pei, "Genetic diversity and differentiation of Camellia sinensis L. (cultivated tea) and its wild relatives in Yunnan province of China, revealed by morphology, biochemistry and allozyme studies," Genetic Resources and Crop Evolution, vol. 52, no. 1, pp. 41-52, 2005.

[14] L. Rajanna, M. Ramakrishnan, and L. Simon, "Evaluation of morphological diversity in South Indian tea clones using statistical methods," Maejo International Journal of Science and Technology, vol. 5, no. 1, pp. 1-12, 2011.

[15] M. A. Aziz, B. Ahmed, M. A. Razvy, M. R. Karim, S. K. L. Haque, and M. Hossain, "Comparative study on some morphological features of six selected and one standard clones of Bangladesh tea [Camellia sinensis (L) O . Kuntze]," International Journal of Biosciences, vol. 1, no. 4, pp. 100-108, 2011.

[16] M.-H. Su, C.-H. Tsou, and C.-F. Hsieh, "Morphological comparisons of Taiwan native wild tea plant (Camellia sinensis (L.) O. Kuntze forma formosensis Kitamura) and two closely related taxa using numerical methods," Taiwania, vol. 52, no. 1, pp. 7083, 2007.

[17] W. Jiang, B. Barshan Özaktaş, N. Mantri, Z. Tao, and H. Lu, "Classification of Camellia species from 3 sections using leaf anatomical data with back-propagation neural networks and support vector machines," Turkish Journal of Botany, vol. 37, no. 6, pp. 1093-1103, 2013.

[18] I. Luna and H. Ochoterena, "Phylogenetic relationships of the genera of Theaceae based on morphology," Cladistics, vol. 20, no. 3, pp. 223-270, 2004.

[19] M. T. K. Gunasekare, J. D. K. Arachchi, A. K. Mudalige, and T. U. S. Peiris, "Morphological diversity of tea (Camellia sinensis L.) genotypes in Sri Lanka," in Proceedings of the 57th Annual Session of Sri Lanka Association for the Advancement of Science (SLAAS '01), vol. 23, Rawatawatte, Moratuwa, Sri Lanka, 2001.

[20] J. H. N. Piyasundara, M. T. K. Gunasekare, and I. P. Wickramasinghe, "Systematic characterization of tea (Camellia sinensis L.) germplasm using morphological descriptors," Tropical Agricultural Research, vol. 20, pp. 193-199, 2008.

[21] H. A. C. K. Ariyarathne and M. T. K. Gunasekare, "Pistil related morphological traits reflect genetic diversity of tea in Sri Lanka," Sri Lanka Journal of Tea Science, vol. 74, no. 1, pp. 1-8, 2009.

[22] IPGRI, Descriptors for Tea (Camellia sinensis), International Plant Genetic Resource Institute, Rome, Italy, 1997.

[23] UPOV, Guidelines for the Conduct of Tests for Distinctness, Uniformity and Stability-Tea, International union for the protection of new varieties of plants (UPOV), Geneva, Switzerland, 2008.

[24] SAS Institute, SAS Version. 9.1 for Windows, SAS Institute, Cary, NC, USA, 2003.

[25] Anon, The Suitability of Tea Clones for The Different Regions TRI Advisory Circular -PN1, Tea Research Institute of Sri Lanka, Sri Lanka, 2002.

[26] R. T. Ellis, "Tea," in Evolution of Crop Plants, J. Smart and N. W. Simmonds, Eds., pp. 22-27, Longman Scientific \& Technical, Harlow, Essex, UK, 1995.

[27] H. B. J. Charles, Seed to Civilization: The Story of Food, vol. 18, Freeman, San Francisco, Calif, USA, 1981.

[28] C. Ariyarathna and K. Gunasekare, "Genetic base of tea (Camellia sinensis L.) cultivars in Sri Lanka as revealed by pedigree analysis," Journal of Applied Genetics, vol. 48, no. 2, pp. 125-128, 2007.
[29] J. K. P. T. P. Jayaweera, I. P. Wickremasinghe, and M. A. B. Ranatunga, "Evaluation of genetic diversity in estate selections of tea (Camellia sinensis L.) using floral characteristics and SSR markers," in Proceedings of the Peradeniya University Research Symposium, 2013.

[30] M. A. B. Ranatunga, H. G. J. Kumudumali, J. D. KottawaArachchi, M. T. K. Gunasekere, and D. M. D. Yakandawala, "Genetic structure of tea (Camellia sinensis (L) O. Kuntze ) germplasm in Sri Lanka: implication on germplasm management and tea breeding," in Proceedings of the Peradeniya University International Research Session Sri Lanka, vol. 18, 2014. 

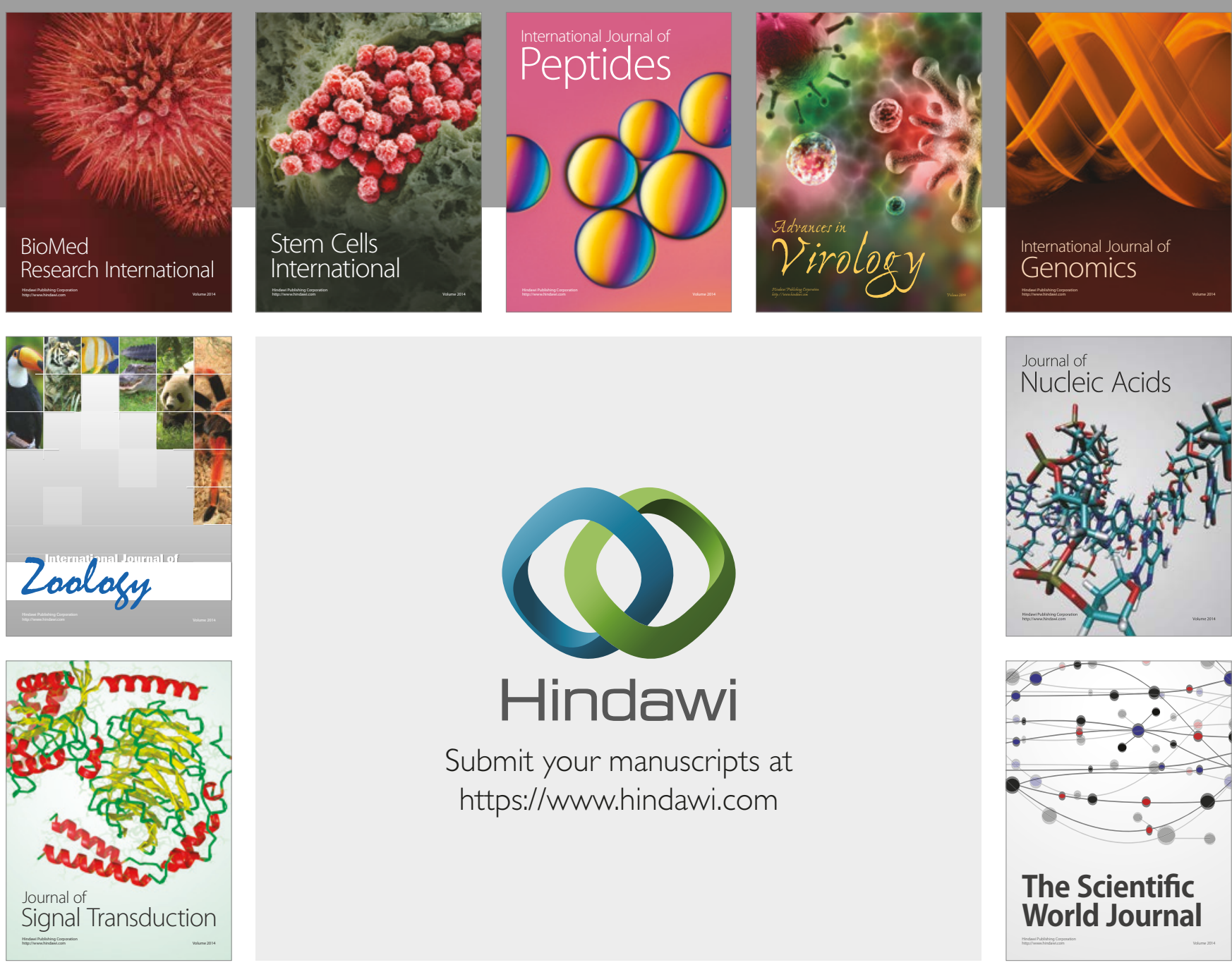

Submit your manuscripts at

https://www.hindawi.com
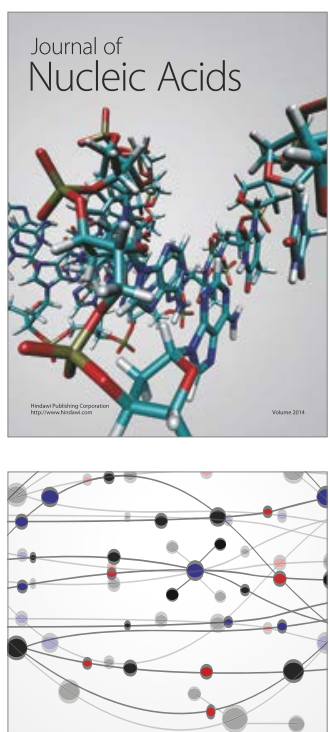

The Scientific World Journal

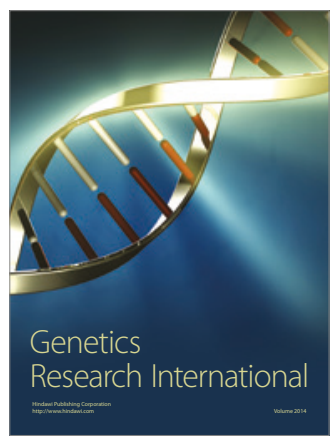

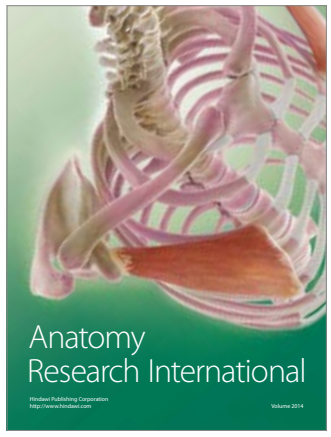

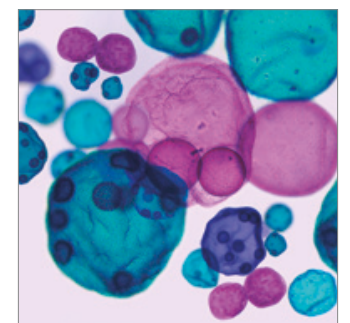

International Journal of Microbiology
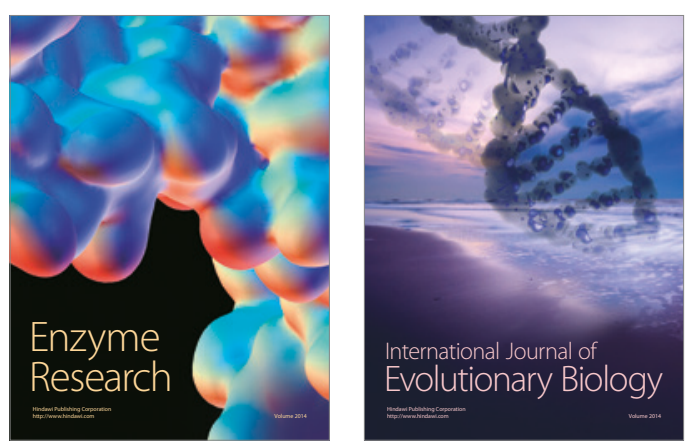
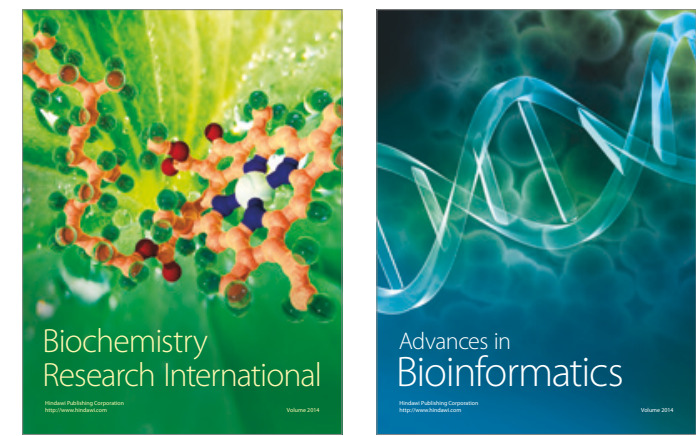

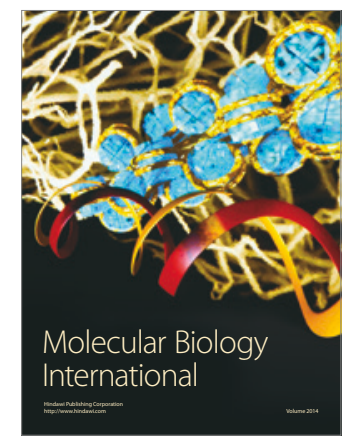

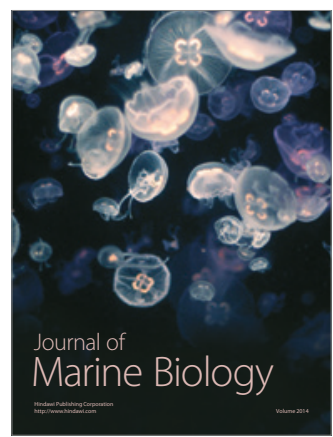

